\title{
Effect of Extended $\pi$-Conjugation of the Donor Structure of Organic D-A- $\pi-A$ Dyes on the Photovoltaic Performance of Dye-Sensitized Solar Cells
}

Masataka Katono, $^{\dagger}$ Mateusz Wielopolski, ${ }^{\ddagger}$ Magdalena Marszalek, ${ }^{\dagger}$ Takeru Bessho, $^{\dagger}$ Jacques-E. Moser, $^{\ddagger}$ Robin Humphry-Baker, ${ }^{\dagger}$ Shaik M. Zakeeruddin, ${ }^{* \dagger}$ and Michael Grätzel ${ }^{*}{ }^{\dagger}$

${ }^{\dagger}$ Laboratory for Photonics and Interfaces and ${ }^{\ddagger}$ Photochemical Dynamics Group, Institute of Chemical Sciences and Engineering, Ecole Polytechnique Fédérale de Lausanne, CH-1015 Lausanne, Switzerland

\section{Supporting Information}

ABSTRACT: Two new D-A- $\pi$-spacer-A organic dyes, KM-10 and KM-11, containing a benzothiadiazole unit in a $\pi$-spacer and a cyanoacrylic acid as an acceptor have been synthesized and tested as sensitizers in dye-sensitized solar cells. Structural variations of the donor moiety, i.e., $\pi$-extension of the diphenylamine electron-donating groups, gave rise to different photovoltaic efficiencies-7.1\% for KM-10 and $8 \%$ for KM-11-despite having comparable absorption properties. A detailed investigation, including transient photocurrent and photovoltage decay measurement, transient absorption spectroscopy, and quantum chemical methods, provided important conclusions about the nature of the substitution on the photovoltaic properties of dyes.

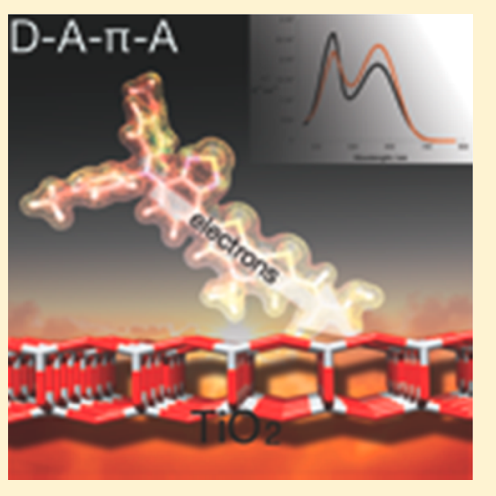

\section{INTRODUCTION}

Dye-sensitized solar cells (DSCs) attracted intensive attention due to their promising potential as solar energy conversion devices. ${ }^{1}$ In the past decade, metal-free organic dyes have been explored for the use in DSCs due to their facile structural modification, high molar absorption, and low cost processability with respect to conventional silicon-based photovoltaic devices. As a result, some sensitizers such as coumarin-, indoline-, and triphenylamine-based dyes have achieved up to $10 \%$ of power conversion efficiencies (PCEs) using iodide-/triiodide-based electrolytes. $^{2-28}$ An efficiency of $12-13 \%$ was reached with a donor $-\pi$-acceptor zinc porphyrin in combination with a cobalt redox-based electrolyte. ${ }^{29-31}$ One of the key issues for the improvement of the photovoltaic performance is enhancing the light-absorbing capability of dyes to match closer the solar spectrum. Hence, the development of new metal-free organic dyes with specifically tuned light-harvesting features continues to be an important research topic.

Recently, organic dye molecules comprising a benzothiadiazole unit have been utilized in DSCs. ${ }^{32-37}$ The benzothiadiazole moiety serves as an electron-deficient acceptor and realizes a broader absorption spectrum and lower HOMO-LUMO band gaps. In this article, we report two novel organic donoracceptor $-\pi$-spacer-acceptor $(\mathrm{D}-\mathrm{A}-\pi-\mathrm{A})$ dyes, KM-10 and KM-11, that contain diphenylamine donors and benzothiadiazole and cyanoacrylic acid acceptors bridged by a cyclopentadithiophene (CPDT) as the $\pi$-spacer. The structures of these two new dyes are shown in Figure 1. The CPDT spacer was employed to enhance the absorption cross-section of the

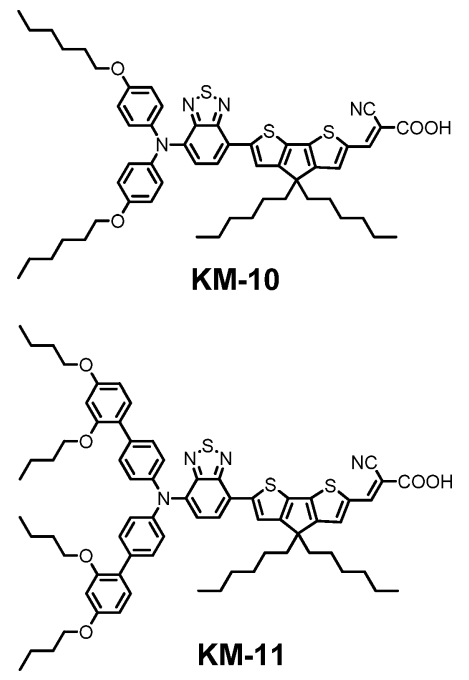

Figure 1. Molecular structures of KM-10 and KM-11.

dyes. $^{8}$ The bulkier donor group of KM-11 as compared with KM-10 was chosen to reduce the dye's aggregation and suppress the charge recombination. To investigate the donor

Special Issue: Michael Grätzel Festschrift

Received: November 22, 2013

Revised: February 25, 2014

Published: February 25, 2014 
Scheme 1. Synthetic Route for the KM-10 and KM-11 Dyes
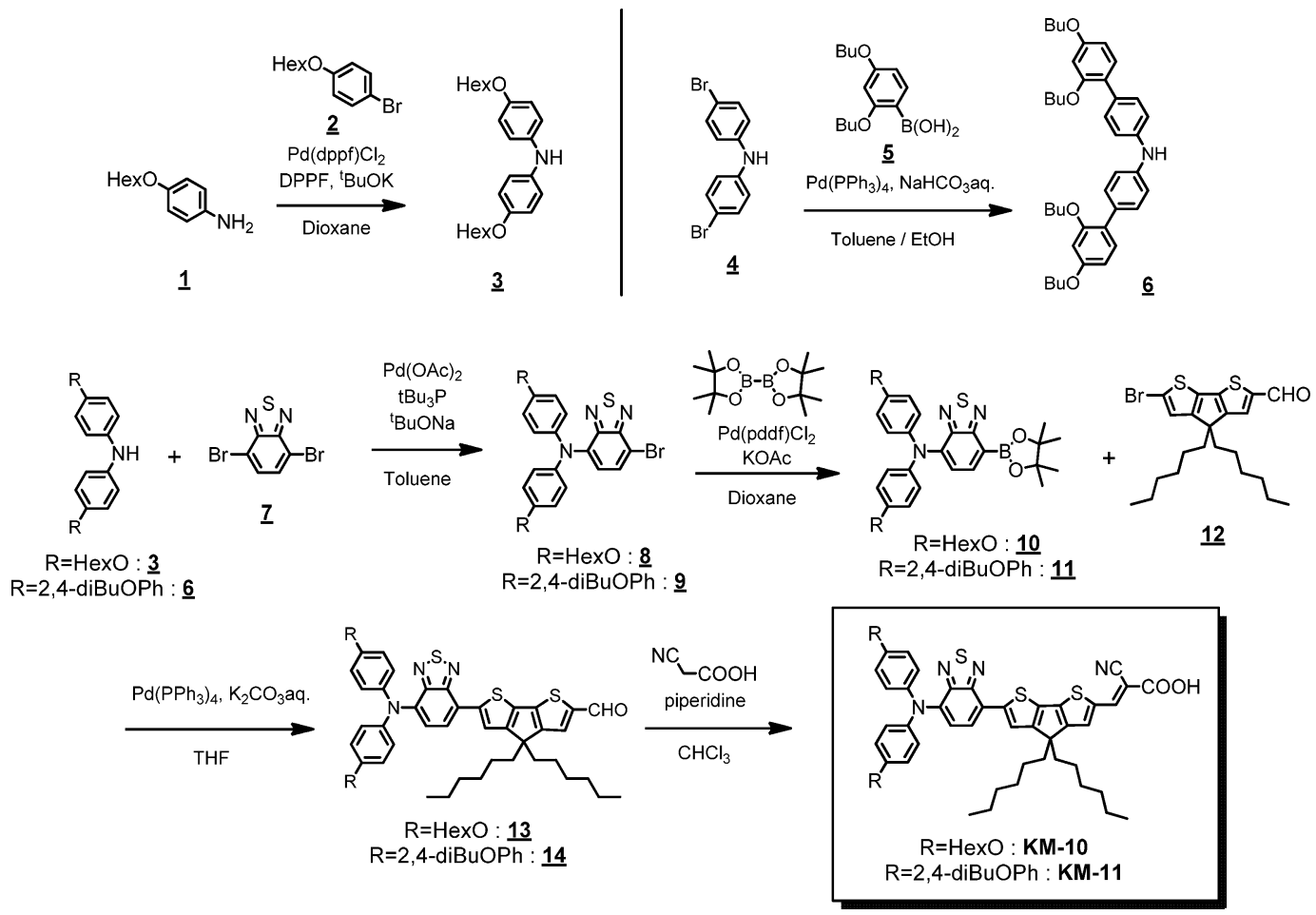

structure influence on the photovoltaic performance of DSC devices, a iodide-/triiodide-based redox electrolyte was applied. The DSC device performance with alternate redox electrolytes will be focused on in future studies.

\section{EXPERIMENTAL SECTION}

Materials. All chemicals and solvents were purchased from commercial sources and used without further purification. For chromatographic purification, we used Silica Gel 60 (230-400 mesh, Merck, Germany).

Instruments. Absorption spectra (Cary 5, Varian), fluorescence spectra (Fluorolog 3, Horiba), and NMR spectra (AVANCE-400, Bruker) were recorded with the indicated instruments. The differential pulse voltammetries (DPVs) of the dyes were measured in DMF solution containing tetrabutylammonium hexafluorophosphate $(0.1 \mathrm{M})$ as a supporting electrolyte with glassy carbon as the working electrode and $\mathrm{Pt}$ as the counter electrode under Ar atmosphere. The redox potentials were calibrated with ferrocene as the internal reference.

Cell Fabrication. State-of-the-art double-layer mesoporous $\mathrm{TiO}_{2}$ layers $(6.6 \mu \mathrm{m}$ of $20 \mathrm{~nm}$ particle (DSL 18NR-T, DYESOL) plus $6.7 \mu \mathrm{m}$ of $400 \mathrm{~nm}$ light-scattering particles (HPW-400NRD, CCIC)) were deposited on FTO conducting glass (Solar-4 mm, Nippon Sheet Glass Co, Ltd.). The doublelayer $\mathrm{TiO}_{2}$ film was sensitized by immersing it into a DMF solution of the respective $\mathrm{KM}$ dye $(0.1 \mathrm{mM})$ for $13 \mathrm{~h}$ at room temperature. The composition of the Z-960 electrolyte was: 1.0 M 1,3-dimethylimidazolium iodide, $30 \mathrm{mM} \mathrm{I}_{2}, 0.5 \mathrm{M}$ tertbutylpyridine, $0.1 \mathrm{M}$ lithium iodide, and $0.1 \mathrm{M}$ guanidinium thiocyanate in a mixture of acetonitrile and valeronitrile (85/15, $\mathrm{v} / \mathrm{v}$ ). A platinized FTO conducting glass (LOF TECH 7, Pilkington) was used as counter electrode.

The spectral distribution of the light source simulates the AM 1.5G solar irradiation characteristics (Xe 450W, K113 filter) with a spectral mismatch of less than $4 \%$. The exposed area of the devices was $0.16 \mathrm{~cm}^{2}$, a black tape mask being used to exclude any stray light. An antireflection film (ARCTOP, Mihama Co.) was attached on the photoanode side.

Photophysical Studies. Time-resolved transient absorption measurements were performed on dye-sensitized, $3 \mu \mathrm{m}$ thick, transparent $\mathrm{TiO}_{2}$ mesoporous films screen-printed on insulating microscope slides. The pump-probe technique used a compact CPA-2001, $1 \mathrm{kHz}$, Ti:Sapphire-amplified femtosecond laser (Clark-MXR), with a pulse width of about 120 fs and a pulse energy of $1 \mathrm{~mJ}$ at a central wavelength of $775 \mathrm{~nm}$. The output beam was split into two parts for pumping a double-stage noncollinear optical parametric amplifier (NOPA) and to produce a white light continuum in a sapphire plate or $387 \mathrm{~nm}$ UV light by second harmonic generation of the CPA output in a thin BBO crystal. The NOPA was pumped by 200 $\mu \mathrm{J}$ pulses generating pulses of approximately $10 \mu \mathrm{J}$ at a wavelength of $580 \mathrm{~nm}$. The output pulses of the NOPA were compressed in an SF10-glass prism pair compressor down to a duration of less than $60 \mathrm{fs}$ (fwhm). Iris diaphragms were used to decrease the pulse energy down to a few microjoules for the pump and to less than $1 \mu \mathrm{J}$ for the probe beam. Transient spectra were measured using a white light continuum (WLC) for probing.

The nanosecond laser flash photolysis employed $7 \mathrm{~ns}$ duration pulses to excite the sample at $\lambda=580 \mathrm{~nm}$, using a $20 \mathrm{~Hz}$ repetition rate. An OPO-355 optical parametric oscillator (GWU, Erftstadt, Germany) pumped by a Powerlite 7030 frequency-tripled Q-switched Nd:YAG laser (Continuum, Santa Clara, California, USA) served as a light source. The OPO beam output was expanded by a planoconcave lens to irradiate a large cross-section of the sample, whose surface was kept at a $30^{\circ}$ angle to the excitation beam. The laser fluence on the sample was kept at a low level $\left(\leq 40 \mu \mathrm{J} \mathrm{cm}^{-2}\right.$ per pulse) to ensure that, on average, less than one electron was injected per 
nanocrystalline $\mathrm{TiO}_{2}$ particle upon pulsed irradiation. The probe light, produced by a continuous wave xenon arc lamp, was first passed through filters, a monochromator tuned between 420 and $720 \mathrm{~nm}$, then through various optical elements, the sample, and finally through a second monochromator, before being detected by a fast photomultiplier tube (Hamamatsu, R9110). Typical recorded signals were averaged over 1000-2000 laser shots.

\section{RESULTS AND DISCUSSION}

Synthesis. The synthetic route of KM-10 and KM-11 is shown in Scheme 1. The diphenylamine donors 3 and 6 were prepared by a monoallylation reaction and Suzuki coupling reaction, respectively. In the next step, these donors were attached to the benzothiadiazole by monoallylation reactions. The dibromo-benzothiadiazole 7 has two reaction sites; however, the pure desired compounds can be easily obtained by column chromatography. The unreacted bromides were exchanged for boronic acid pinacol ester, leading subsequently to a Suzuki coupling reaction between boronic acid $\mathbf{1 0}$ and 11, and the CPDT segment $\mathbf{1 2}$ gave the aldehyde compounds. The functionalized CPDT compound $\mathbf{1 2}$ was synthesized by the previously reported method. ${ }^{2}$ Finally, a typical Knoevenagel condensation of the aldehydes 13 and $\mathbf{1 4}$ and 2-cyanoacetic acid as the acceptor and anchoring group afforded the novel photosensitizers, KM-10 and KM-11, respectively. The dyes are obtained as dark red solids and dissolve in several organic solvents, such as dichloromethane, chloroform, DMF, and DMSO.

Optoelectronic Properties. The excitation and emission spectra of KM-10 and KM-11 dyes adsorbed on thin $\mathrm{TiO}_{2}$ films are shown in Figure 2. The absorption spectra of KM-10 and

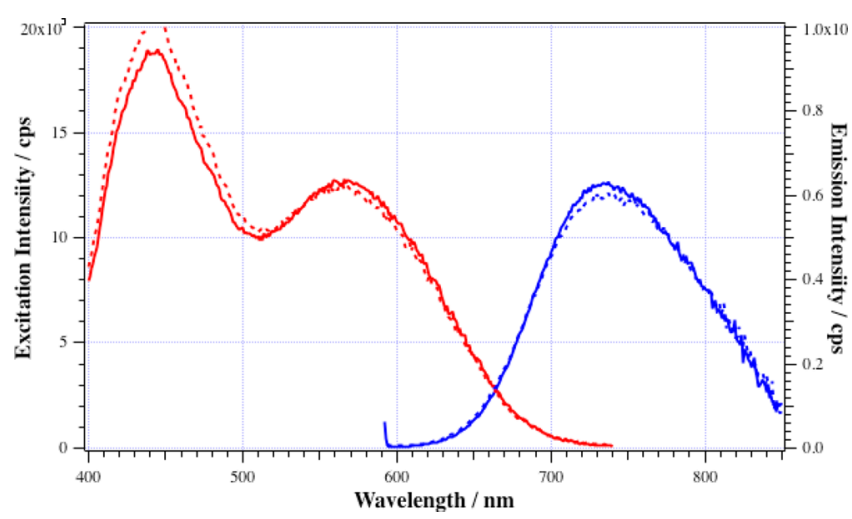

Figure 2. Excitation spectrum measured at an emission wavelength of $750 \mathrm{~nm}$ (red) for KM-10 (solid line) and KM-11 (dashed line) as adsorbed on the surface of a thin $\mathrm{TiO}_{2}$ layer deposited by ALD and the corresponding emission at an excitation of $460 \mathrm{~nm}$ (blue).

KM-11 dyes measured in dichloromethane solution in the acid and deprotonated form are shown in Figure S1 (Supporting
Information). The extension of the $\pi$-system for the electrondonating diphenylamine (DA) moiety does not lead to a significant change in the position of the absorption bands. For both dyes in the protonated form, two maxima are observedone around $498 \mathrm{~nm}$ and another at $600 \mathrm{~nm}$. Their relative intensities differ from each other and lead to molar extinction coefficients of 11000 and $20700 \mathrm{M}^{-1} \cdot \mathrm{cm}^{-1}$ for KM-10 as well as 11160 and $21200 \mathrm{M}^{-1} \cdot \mathrm{cm}^{-1}$ for $\mathrm{KM}-11$ as presented in Table 1 . The longer-wavelength peak is due to the $\pi-\pi^{*}$ charge transfer (CT) transitions from the donor to the cyanoacrylic acid acceptor. The shorter-wavelength absorption band (400$500 \mathrm{~nm}$ ) appeared because of the introduction of a 2,1,3benzothiadiazole moiety as a spacer. However, the overall $\pi$ conjugation length is not affected by the extension of the donor $\pi$-system, which is the reason for the lack of a shift of the KM11 absorption maxima. The effect of substituting the phenyl ring of C218 with the electron-accepting benzothiadiazole is clearly reflected in red shifting the low-lying transition by 45 $\mathrm{nm}$ with lower molar extinction coefficients. ${ }^{8}$ The absorption spectra of KM-10 and KM-11 are more red-shifted compared to other benzothiadiazole analogues reported previously, which is due to the direct attachment of a diphenylamine nitrogen to the benzothiadiazole. ${ }^{32-37}$

The redox potentials of KM-10 and KM-11 dyes were measured by differential pulse voltammetry (DPV), and the values are tabulated in Table 1 . The redox potential of the KM10 and KM-11 dyes is 0.23 and $0.3 \mathrm{~V}$ more positive than ferrocene, respectively. The redox potential is higher than that of the iodide/triiodide redox electrolyte, providing ample driving force for dye regeneration. The structural differences in the donor groups of KM-10 and KM-11 have a small influence on their redox potentials, and the redox potential of KM-11 dye is increased by $70 \mathrm{mV}$ compared to KM-10. The excited state reduction potentials of KM-10 and KM-11 were obtained from the redox potentials and the energy of the $0-0$ transition $\left(E_{0-0}\right)$. The excited state potentials are placed sufficiently above the $\mathrm{TiO}_{2}$ conduction band edge to ensure no energetic barriers for the electron injection.

Theoretical Calculations. The molecular structures and electronic properties of the dyes were investigated at the density functional theory (DFT) level using the B3LYP ${ }^{38}$ functional with a $6-31 \mathrm{G}^{* 39}$ basis set as implemented into the Gaussian $09^{40}$ suite of programs. The optimized geometries are shown in Figure 3. The structural differences between the two dyes are rather subtle. Characteristic for both dyes is that the linker between the DA donor and the anchoring group is entirely planar, which promotes complete conjugation throughout the whole structure. Furthermore, the planarity is retained upon oxidation of the molecules, as shown by calculations of the structure for the cation radicals of KM-10 and KM-11.

The representation of the frontier molecular orbitals (Figure 4) corroborates the extended $\pi$-conjugation. Orbital coefficients of the highest occupied molecular orbital (HOMO) and the

Table 1. Optical ${ }^{a}$ and Electrochemical Properties of Dyes

\begin{tabular}{|c|c|c|c|c|c|c|c|c|c|c|}
\hline dye & $\lambda_{\max }(\mathrm{nm})$ & $\varepsilon\left(\mathrm{M}^{-1} \cdot \mathrm{cm}^{-1}\right)$ & $\begin{array}{l}\mathrm{HOMO} \\
(\mathrm{eV})\end{array}$ & $\begin{array}{l}\text { LUMO } \\
(\mathrm{eV})\end{array}$ & $\begin{array}{c}\text { HOMO } \\
(\mathrm{DFT})\end{array}$ & $\begin{array}{l}\text { LUMO } \\
\text { (DFT) }\end{array}$ & $\begin{array}{l}E_{\text {oxl }}^{0} \\
(\mathrm{~V})\end{array}$ & $\begin{array}{l}E_{\text {ox } 2}^{0} \\
(\mathrm{~V})\end{array}$ & $\begin{array}{l}\Delta E_{0-0} \\
(\mathrm{eV})\end{array}$ & $\begin{array}{c}E_{\text {ox1 }}^{0}-\left(\Delta E_{0-0}\right) \\
(\mathrm{V})\end{array}$ \\
\hline KM-10 & 498,600 & 11000,20706 & -5.45 & -3.50 & -4.56 & -2.29 & 0.23 & 0.43 & 1.85 & -0.90 \\
\hline KM-11 & 496,598 & 11160,21200 & -5.52 & -3.47 & -4.57 & -2.41 & 0.30 & 0.45 & 1.85 & -0.83 \\
\hline
\end{tabular}

${ }^{a} \mathrm{CH}_{2} \mathrm{Cl}_{2}$ as a solvent. All potential values are in $\mathrm{V}$ vs $\mathrm{Fc}^{+} / \mathrm{Fc}$. Dyes were dissolved in DMF. Standard redox potential of a $\mathrm{Fc}^{+} / \mathrm{Fc}$ couple in DMF is $0.720 \mathrm{~V}$ vs SHE. 


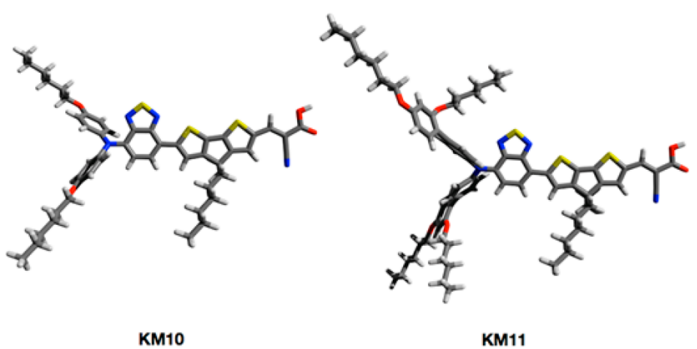

Figure 3. Optimized geometries of KM-10 and KM-11 as computed using DFT theory at the $\mathrm{B} 3 \mathrm{LYP} / 6-31 \mathrm{G}^{*}$ level showing the planar configuration of the linker between the DA donor and the anchoring group.

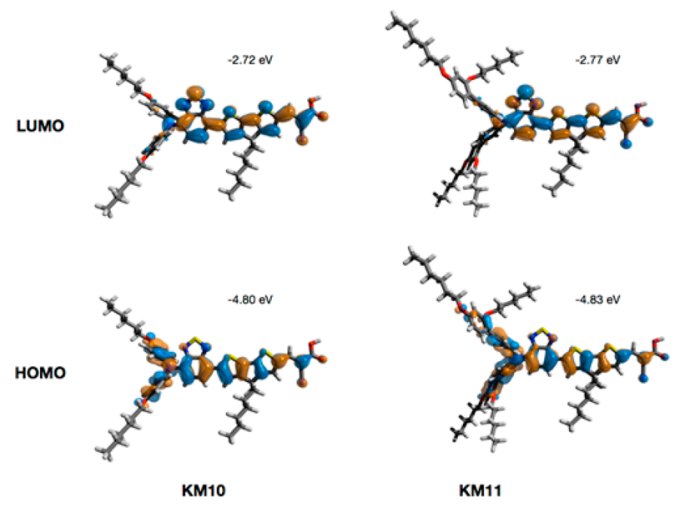

Figure 4. Representation of the highest occupied (HOMO) and lowest unoccupied (LUMO) molecular orbitals of KM-10 and KM-11 with the corresponding orbital energies in vacuum as computed using DFT theory at the B3LYP/6-31G* level.

lowest unoccupied molecular orbital (LUMO) are extended over the whole system. This guarantees efficient electronic communication between the DA donor and the cyanoacrylic acid acceptor and is reflected in extremely fast charge separation processes as discussed in the photophysical part. Important in this regard is the fact that the insertion of the additional phenyl rings in KM-11 does not perturb the overall conjugation length. The LUMO in KM-11 is slightly lower in energy (by $0.07 \mathrm{eV}$ ) and the HOMO slightly higher (by 0.03 $\mathrm{eV}$ ) compared to KM-10, which leads to a smaller HOMOLUMO energy gap and would lower the excitation energy for a HOMO to LUMO charge transfer excitation.

The significance of these structural changes is best seen when plotting the electrostatic potential of the calculated oxidized states (charge $=+1$ ) of the dyes as shown in Figure 5. The plots

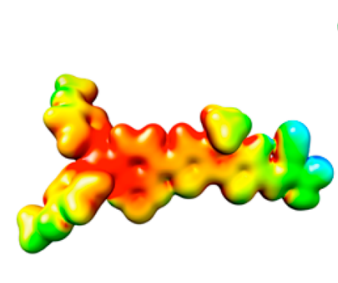

KM10

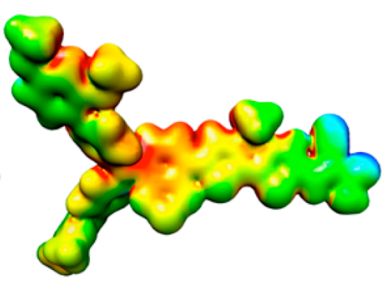

KM11
Figure 5. Representation of the electrostatic potential as mapped on the electron density surface (positive to negative: red to blue) of the optimized cationic forms of KM-10 and KM-11 dyes. KM-10 exhibits strong localization of the positive charge around the DA nitrogen (red color). show that after oxidation the positive charge in KM-10 is strongly localized on the DA nitrogen. In KM-11, on the other hand, the extended $\pi$-conjugation allows for a better spatial delocalization of the positive charge over the entire DA moiety. Such a delocalization and the lower HOMO-LUMO energy gap stabilize the excited charge transfer state and explain the long-lived oxidized species of KM-11 as compared with KM-10 (see the Time-Resolved Spectroscopy section).

Photovoltaic Properties. DSC devices were fabricated using KM-10 and KM-11 dyes to compare the influence of the structural variations of dyes on the photovoltaic parameters. The photocurrent-voltage curve and the incident photon to current conversion efficiency (IPCE) of the KM-11 device are shown in Figure 6. For KM-11 the maximum IPCE value
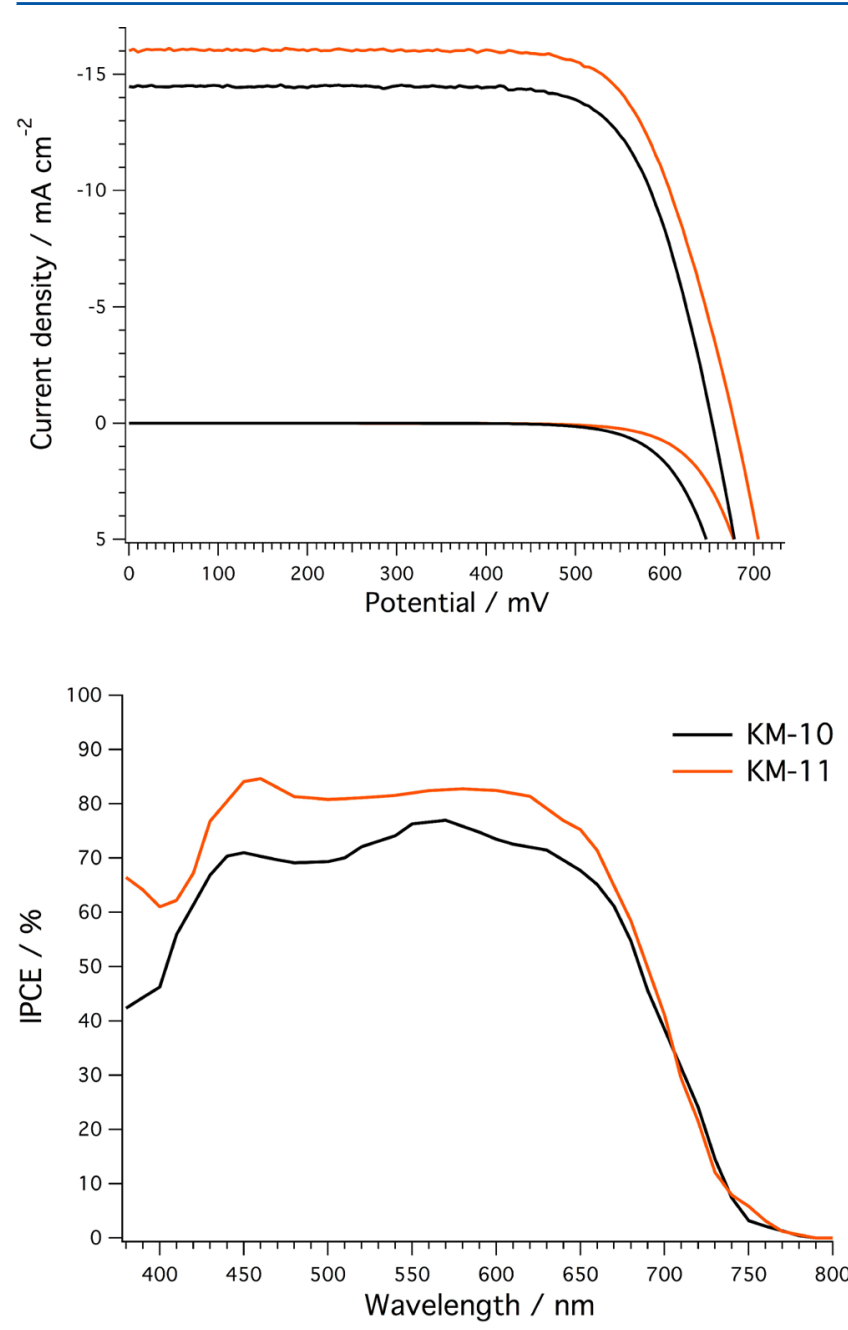

Figure 6. Incident photon-to-current conversion efficiency (IPCE) spectra of the DSCs with the KM-10 and KM-11 dyes.

reached $85 \%$ at $450 \mathrm{~nm}$, exceeding $80 \%$ from the 430 to 650 $\mathrm{nm}$ range with an onset up to $750 \mathrm{~nm}$. The photovoltaic parameters of the devices are tabulated in Table 2. The 6-7bis $\left(2^{\prime}, 4^{\prime}\right.$-dibutoxy-[1,1'-biphenyl]-4-yl)amino donor in KM-11 as compared with a 6-7-bis(4-(hexyloxy)phenyl) amino group in KM-10 is responsible for the enhancement of the photovoltaic conversion efficiency due to an increase in $J_{\text {sc }}$ and $V_{\mathrm{oc}}$ values. Overall, power conversion efficiencies (PCEs) of $7.1-8.0 \%$ are obtained for the KM-10 and KM-11 devices, respectively. 
Table 2. Photovoltaic Parameters of KM-10 and KM-11 Sensitized Solar Cells under Illumination of AM 1.5G (100 $\mathrm{mW} \mathrm{cm}^{-2}$ ) Simulated Solar Light

\begin{tabular}{ccccc}
\hline dye & $J_{\text {sc }}\left(\mathrm{mA} \mathrm{cm}^{-2}\right)$ & $V_{\text {oc }}(\mathrm{mV})$ & $\mathrm{FF}$ & $\eta(\%)$ \\
KM-10 & 14.5 & 653 & 0.742 & 7.1 \\
KM-11 & 16.0 & 678 & 0.732 & 8.0 \\
\hline
\end{tabular}

The $25 \mathrm{mV}$ increase in the $V_{\text {oc }}$ of the KM-11 device may be attributed to the change of the electron recombination kinetics. Transient photovoltage experiments give access to the apparent electron lifetime-time that the injected electron resides in $\mathrm{TiO}_{2}$ before it recombines. When plotted against the cell capacitance, which is linearly tied to the density of states, measured under decreasing light illumination, electron lifetime should exhibit a linear growth, which is presented in Figure 7.
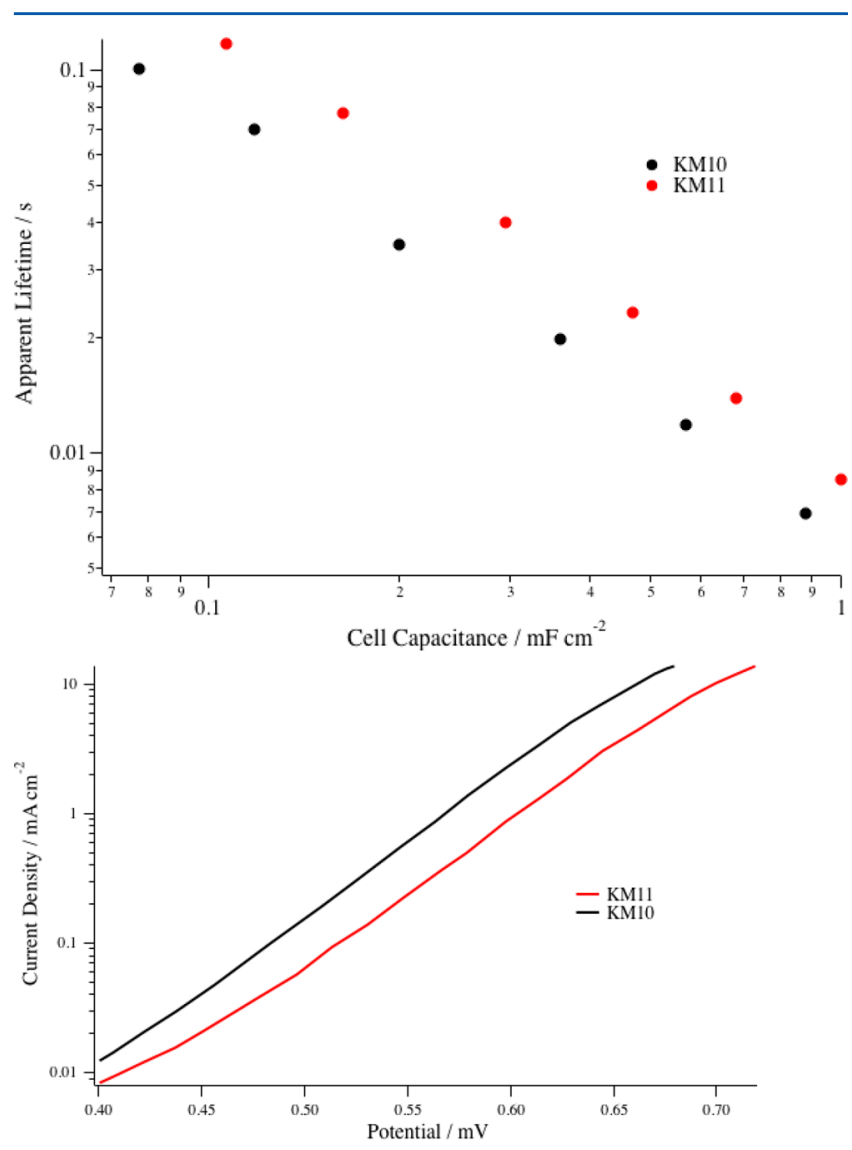

Figure 7. Top: Apparent electron lifetime plotted against the cell capacitance for cells sensitized with dyes KM-10 (black) and KM-11 (orange). Bottom: The comparison of dark currents of the devices in the appropriate range of applied potential.

There is a shift between these parallel lines indicating that shorter lifetimes were measured for the device with KM-10 dye at the same density of states level. The dark current is essentially the recombination current and reveals the robustness of the dye at the $\mathrm{TiO}_{2} /$ electrolyte interface. The comparison of the dark currents of the two devices shows clearly that the recombination rate of the cell with KM-10 is higher than that of KM-11 because the amount of the leaking current is larger. Extending the donor part by an additional 6(7-(bis $\left(2^{\prime}, 4^{\prime}\right.$-dibutoxy-phenyl $\left.)\right)$ ) ring on KM-11 improved shielding of the $\mathrm{TiO}_{2}$ surface from the oxidized form of the electrolyte and contributed to much higher photocurrent generation. The interface seems to be more resistant, and this is manifested in the higher $V_{\text {oc }}$.

Time-Resolved Spectroscopy. To investigate the charge transfer properties of the dyes and their kinetics in solution as well as after adsorption on $\mathrm{TiO}_{2}$ we have employed timeresolved transient absorption spectroscopic techniques on the femto- and nanosecond time scales. Important conclusions about the spectroscopic fingerprints of the excited state species of the dyes were obtained by femtosecond transient absorption studies on $0.1 \mathrm{mM}$ solutions of the dyes in dimethylformamide (DMF). $580 \mathrm{~nm}$ laser excitation leads to an immediate formation of the dyes' excited states. Due to the donoracceptor type architecture the excitation results in an intramolecular electron transfer between the DA donor moiety and the cyanoacrylic acid acceptor/anchoring unit. In both dyes these charge-separated states are characterized by the signature of the positively charged diphenylamine radical cation $\left(\mathrm{DA}^{\bullet+}\right)$, which is identified by a ground state bleaching signal at wavelengths between 400 and $550 \mathrm{~nm}$ and a new positive absorption feature between 620 and $750 \mathrm{~nm}$ (Figure 8a). The
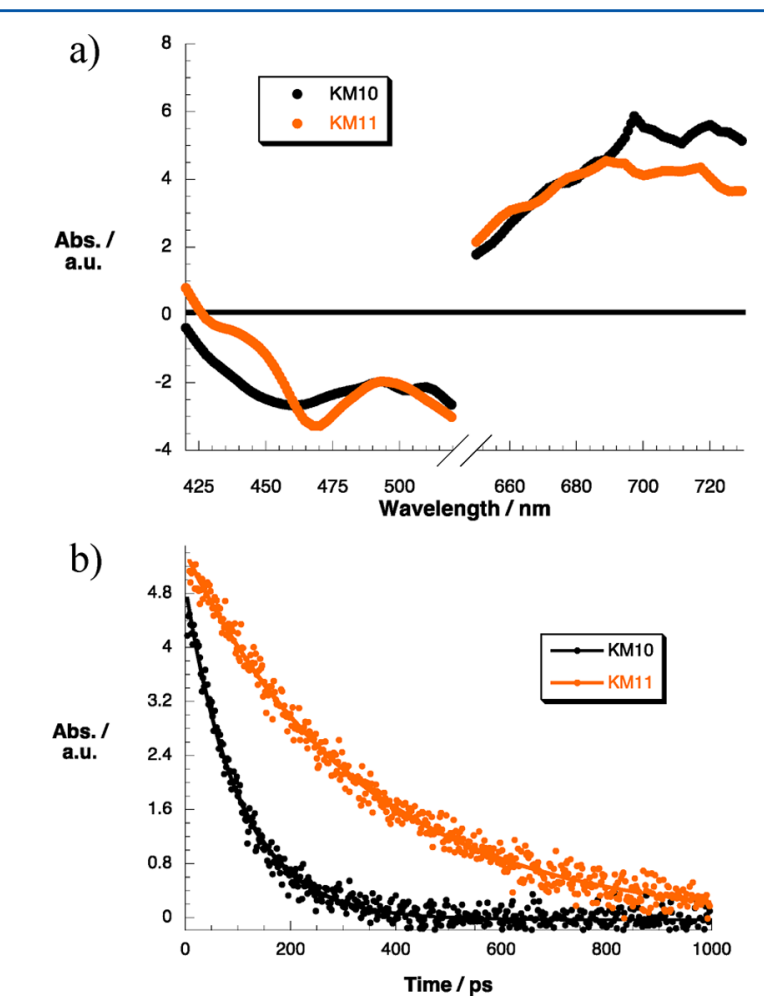

Figure 8. (a) Differential transient absorption spectrum obtained upon femtosecond pulsed laser excitation $\left(\lambda_{\mathrm{exc}}=580 \mathrm{~nm}\right)$ of $0.1 \mathrm{mM}$ DMF solutions of KM-10 and KM-11 probed with a time delay of 2 ps at room temperature. The spectral region around $580 \mathrm{~nm}$ excitation is omitted for clarity. (b) Corresponding time profiles monitored at a probe wavelength of $680 \mathrm{~nm}$ illustrating the different decay kinetics of the radical cation signal of both dyes.

formation of those excited states occurs for both dyes with comparable kinetics within less than 2 ps (Table 3). Differences arise when looking at their lifetimes. In KM-11 the dye excited state exhibits more than a 3 -fold increase of its lifetime as compared with KM-10 (Figure 8b). The reason for this difference in deactivation kinetics is the distribution of the positive charge after charge separation. The additional 6-(7(bis $\left(2^{\prime}, 4^{\prime}\right.$-dibutoxy-phenyl $\left.)\right)$ ) rings and enhanced conjugation 
Table 3. Charge Injection $\left(k_{\mathrm{CI}}\right)$ and Charge Recombination Rate Constants $\left(k_{\mathrm{CR}}\right)$ for KM-10 and KM-11 in 0.1 mM DMF Solutions and on $3 \mu \mathrm{m} \mathrm{TiO}_{2}$ Films with and without a Redox Electrolyte (EL) as Obtained by Femtosecond Transient Absorption Measurements and Nanosecond Flash Photolysis with $580 \mathrm{~nm}$ Light Excitation

\begin{tabular}{lcccc} 
& $k_{\mathrm{CI}} / \mathrm{s}^{-1}$ & $k_{\mathrm{ED}} / \mathrm{s}^{-1}$ & $\tau_{1 / 2}(\mathrm{CI})$ & $\tau_{1 / 2}(\mathrm{ED})$ \\
$\mathrm{DMF}$ & & & & \\
$\mathbf{K M}-10$ & $1.9 \times 10^{12}$ & $9.8 \times 10^{9}$ & $<1 \mathrm{ps}$ & $102 \mathrm{ps}$ \\
$\mathbf{K M}-11$ & $1.3 \times 10^{12}$ & $2.9 \times 10^{9}$ & $<1 \mathrm{ps}$ & $345 \mathrm{ps}$ \\
$\mathrm{TiO}_{2}$ no EL & & & & \\
$\mathrm{KM}^{-10}$ & $1.1 \times 10^{12}$ & $2.3 \times 10^{4}$ & $\sim 1 \mathrm{ps}$ & $43.5 \mu \mathrm{s}$ \\
$\mathbf{K M}-11$ & $0.9 \times 10^{12}$ & $1.6 \times 10^{3}$ & $\sim 1 \mathrm{ps}$ & $636 \mu \mathrm{s}$ \\
$\mathrm{TiO}_{2}$ with EL & & & & \\
$\mathrm{KM}^{210}$ & $2.4 \times 10^{12}$ & $2.7 \times 10^{5}$ & $<1 \mathrm{ps}$ & $3.66 \mu \mathrm{s}$ \\
$\mathbf{K M}-11$ & $1.7 \times 10^{12}$ & $1.5 \times 10^{5}$ & $<1 \mathrm{ps}$ & $6.59 \mu \mathrm{s}$ \\
\hline
\end{tabular}

in KM-11 allow for a better spatial delocalization of the positive charge, which in turn helps to stabilize the excited state. This corresponds well with the results obtained in the theoretical studies (see Theoretical Calculations section).

The femtosecond transient absorption spectra of the dyesensitized $\mathrm{TiO}_{2}$ films exhibit spectral fingerprints of the DA radical cation comparable to those found in solution studieshowever red-shifted and with different kinetics. The significantly broadened bleaching appears now at 460-670 nm, and the $\mathrm{DA}^{\bullet+}$ maximum is shifted beyond $680 \mathrm{~nm}$ (Figure 9). The
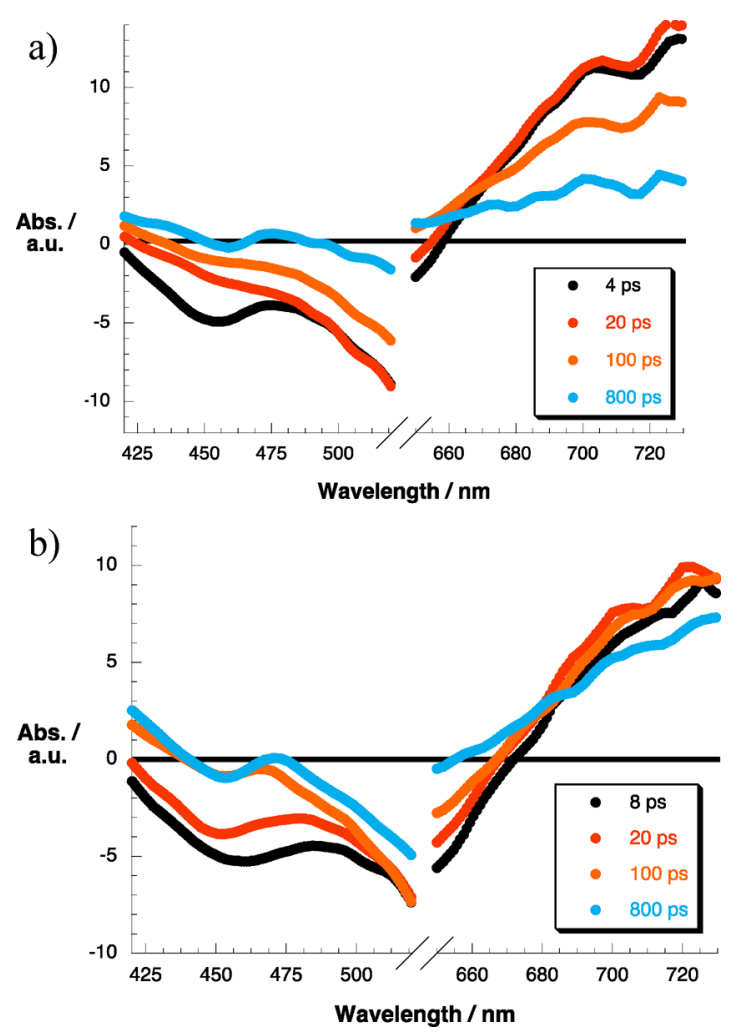

Figure 9. (a) Differential absorption spectrum of KM-10 obtained upon femtosecond flash photolysis $\left(\lambda_{\text {exc }}=580 \mathrm{~nm}\right)$ of $3 \mu \mathrm{m}$ thick transparent $\mathrm{TiO}_{2}$ films without electrolyte and with several time delays at room temperature showing the singlet bleach from 460 to $670 \mathrm{~nm}$ and the radical cation maximum beyond $670 \mathrm{~nm}$. (b) Corresponding differential absorption spectrum of KM-11. The spectral regions around the $580 \mathrm{~nm}$ excitation are omitted for clarity. broadening and the red shift of the signals stem from the electronic interactions with $\mathrm{TiO}_{2}$. The adsorption of the dyes onto the semiconductor surface induces intermolecular interactions between individual molecules and a shift of charge density onto $\mathrm{TiO}_{2}$, which in turn broadens the signals and lowers their excitation energies.

The charge transfer kinetics has been investigated in the presence and in the absence of a redox-active electrolyte (Z960). In a redox medium the charged molecules of the electrolyte tend to stabilize the generated positive charge and favor the charge injection, which may result in marginal differences between the charge injection kinetics in the presence and absence of the electrolyte. In general, on $\mathrm{TiO}_{2}$ extremely fast charge injection on time scales of only a few picoseconds is observed for both systems (Table 3). Although the comparison of charge injection kinetics in this time regime is laborious due to the limitations of our experimental setup, exponential fitting of the signals corresponding to the excited state formation (Figure S2, Supporting Information) hints to slightly faster charge injection rate constants in KM-11. Again, the improved delocalization of the positive charge on KM-11 induces stabilization effects, which may be considered to trigger a faster charge injection.

Nanosecond flash photolysis experiments were performed to scrutinize the fate of the long-lived charge-separated species of the dyes adsorbed on $\mathrm{TiO}_{2}$. Thereby, the spectral attributes of the $\mathrm{DA}^{\bullet+}$ radical cation, i.e., ground state bleaching between 440 and $660 \mathrm{~nm}$ and the absorption maximum beyond $680 \mathrm{~nm}$, served as a probe of the oxidized state of the dye, as well (Figure 10).
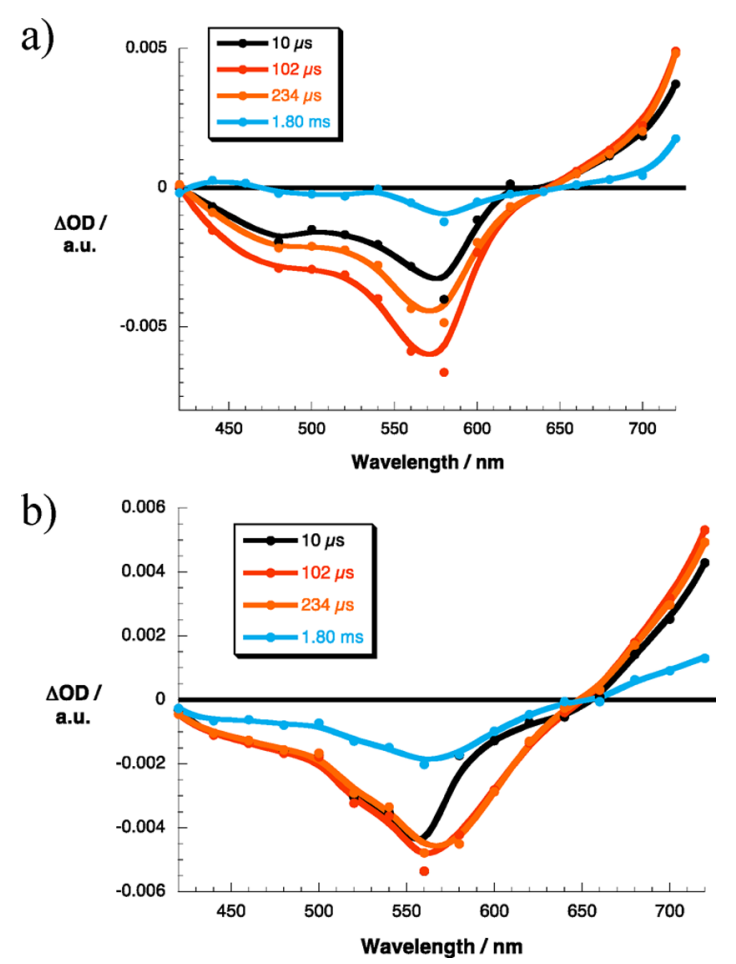

Figure 10. (a) Differential absorption spectrum obtained upon nanosecond flash photolysis $\left(\lambda_{\text {exc }}=580 \mathrm{~nm}\right)$ of KM-10 on $3 \mu \mathrm{m}$ thick $\mathrm{TiO}_{2}$ in the absence of a redox electrolyte solution with several time delays at room temperature. (b) Corresponding differential absorption spectrum of KM-11. 
In the absence of the redox electrolyte the temporal analysis of the decays of the radical cation signals at 540 and $680 \mathrm{~nm}$ reveals the most significant differences between KM-10 and KM-11. Without the iodide ion in the electrolyte, the electrons injected into the $\mathrm{TiO}_{2}$ can only recombine with the oxidized dye. The charge recombination rate constant for KM-10 was determined to $2.3 \times 10^{4} \mathrm{~s}^{-1}$, which gives a 14-times faster charge recombination lifetime than for KM-11 with $k_{\mathrm{CR}}=$ $1.6 \times 10^{3} \mathrm{~s}^{-1}$ (Table 3). Again, this is well explained by the outcome of our theoretical investigation. Due to enhanced spatial delocalization of the positive charge on the DA donor moiety in KM-11 its oxidized state is stabilized which retards the charge recombination kinetics.

The addition of the iodide redox electrolyte confirms that the charge recombination kinetics (photo-injected electrons into the conduction band of $\mathrm{TiO}_{2}$ ) with the oxidized form of the dye only depend on the structural differences of the two dyes (Figure 11). Hence, in the presence of iodide, the lifetimes of

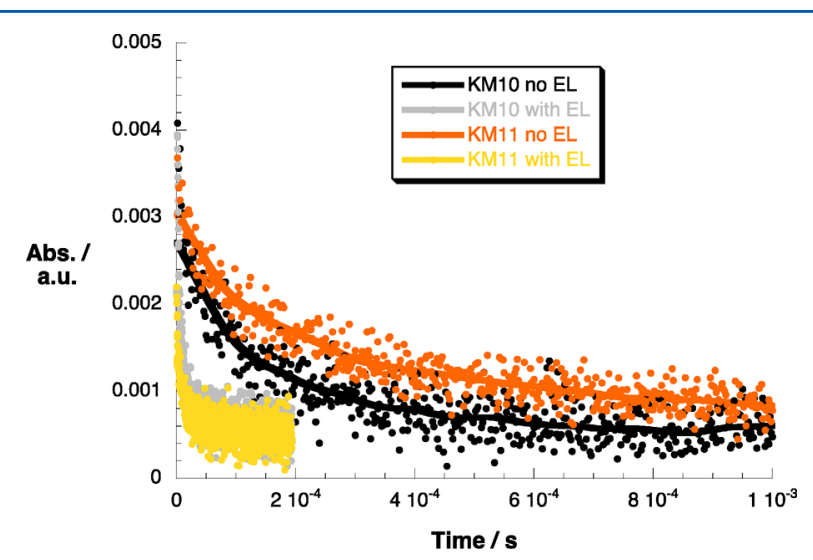

Figure 11. Time profiles of transient absorption monitored at $\lambda=680$ nm of $\mathrm{TiO}_{2}$ films sensitized by KM-10 and KM-11 with and without electrolyte (EL) solution as obtained from nanosecond flash photolysis studies $\left(\lambda_{\text {exc }}=580 \mathrm{~nm}\right)$. Traces show the slow decay of the radical cation signal in the absence of the electrolyte and its acceleration after addition of iodide.

the charge-separated states drastically decrease by a factor greater than 10 for KM-10 (from 43.5 to $3.66 \mu \mathrm{s}$ ) and almost 100 for KM-11 (from 636 to $6.59 \mu \mathrm{s}$ ) (Table 3). The similarity of the regeneration times arises from the fact that in the redox electrolyte the oxidized dye is reduced back to the neutral state via electron donation from iodide, which is faster than the back electron transfer from $\mathrm{TiO}_{2}$ and is not affected strongly by the structural differences between the two dyes. Hence, their chemical architecture significantly impacts the charge recombination and the amount of electrons present in $\mathrm{TiO}_{2}$ before recombination.

\section{CONCLUSIONS}

Two novel organic dyes containing a benzothiadiazole acceptor unit part of a $\mathrm{D}-\mathrm{A}-\pi$-spacer $-\mathrm{A}$ structure featuring cyanoacrylic acid as a second terminal acceptor/anchoring group have been synthesized for the application in DSCs. Photophysical investigation in combination with quantum chemical methods have shown favorable light-harvesting properties of both the dyes. The extension of the $\pi$-system within the diphenylamine donor moiety in KM-11 leads to improved photovoltaic performance of the corresponding devices with a maximum PCE of $8.0 \%$ at AM $1.5 \mathrm{G}$ illumination $\left(100 \mathrm{~mW} \mathrm{~cm}^{-2}\right)$. These promising results obtained by judicious arrangement of the four simple structural units of these sensitizers warrant further investigations to explore, e.g., the effects of the extension of the $\pi$-system in the spacer moiety between the donor and acceptor within comparable dye architectures.

\section{ASSOCIATED CONTENT}

\section{Supporting Information}

Synthesis of dyes, absorption spectra of dyes in acid and deprotonated form, and exponential fits of the time profiles of excited state formation in DMF solutions of KM-10 and KM11 and $\mathrm{TiO}_{2}$ films sensitized by KM-10 and KM-11 with and without electrolyte (EL). This material is available free of charge via the Internet at http://pubs.acs.org.

\section{AUTHOR INFORMATION}

\section{Corresponding Authors}

*E-mail: shaik.zakeer@epfl.ch.

*E-mail: michael.graetzel@epfl.ch.

\section{Notes}

The authors declare no competing financial interest.

\section{ACKNOWLEDGMENTS}

We are grateful to Dr. Tsuguo Koyanagi from JGC C\&C (Japan), Nippon Sheet Glass Co., Ltd., and Mihama Co. for providing the $400 \mathrm{~nm}$ sized $\mathrm{TiO}_{2}$ particles the FTO glass and antireflection layer, respectively. M.K. is grateful to the Kureha Corporation for his scholarship. M.G. is thankful to the Swiss National Science Foundation (Swiss-Romanian Joint Research Programme) and an advanced research grant (ARG) from the European Research Council (ERC) supporting the Mesolight project under project number 247404. M.W. and J.-E.M. thank NCCR MUST, a research instrument of the Swiss National Science Foundation, for support.

\section{REFERENCES}

(1) O’Regan, B.; Grätzel, M. A Low-Cost, High-Efficiency Solar Cell Based on Dye-Sensitized Colloidal $\mathrm{TiO}_{2}$ Films. Nature 1991, 353, 737-740.

(2) Kitamura, T.; Ikeda, M.; Shigaki, K.; Inoue, T.; Anderson, N. A.; Ai, X.; Lian, T.; Yanagida, S. Phenyl-Conjugated Oligoene Sensitizers for $\mathrm{TiO}_{2}$ Solar Cells. Chem. Mater. 2004, 16, 1806-1812.

(3) Jung, I.; Lee, J. K.; Song, K. H; Song, K.; Kang, S. O.; Ko, J. Synthesis and Photovoltaic Properties of Efficient Organic Dyes Containing the Benzo[b]Furan Moiety for Solar Cells. J. Org. Chem. 2007, 72, 3652-3658.

(4) Hagberg, D. P.; Yum, J.-H.; Lee, H.; De Angelis, F.; Marinado, T.; Karlsson, K. M.; Humphry-Baker, R.; Sun, L.; Hagfeldt, A.; Grätzel, M.; et al. Molecular Engineering of Organic Sensitizers for DyeSensitized Solar Cell Applications. J. Am. Chem. Soc. 2008, 130, 62596266.

(5) Ning, Z.; Zhang, Q.; Wu, W.; Pei, H.; Liu, B.; Tian, H. Starburst Triarylamine Based Dyes for Efficient Dye-Sensitized Solar Cells. J. Org. Chem. 2008, 73, 3791-3797.

(6) Chang, Y. J.; Chow, T. J. Dye-Sensitized Solar Cell Utilizing Organic Dyads Containiong Triarylene Conjugates. Tetrahedron 2009, 65, 4726-4734.

(7) Baheti, A.; Tyagi, P.; Thomas, K. R. J.; Hsu, Y.-C.; Lin, J. T. Simple Triarylamine-Based Dyes Containing Fluorine and Biphenyl Linkers for Efficient Dye-Sensitized Solar Cells. J. Phys. Chem. C 2009, $113,8541-8547$.

(8) Li, R.; Liu, J.; Cai, N.; Zhang, M.; Wang, P. Synchronously Reduced Surface States, Charge Recombination, and Light Absorption Length for High-Performance Organic Dye-Sensitized Solar Cells. J. Phys. Chem. B 2010, 114, 446-4464. 
(9) Koumura, N.; Wang, Z.-S.; Mori, S.; Miyashita, M.; Suzuki, E.; Hara, K. Alkyl-Functionalized Organic Dyes for Efficient Molecular Photovoltaics. J. Am. Chem. Soc. 2006, 128, 14256-14257.

(10) Kim, D.; Lee, J. K.; Kang, S. O.; Ko, J. Molecular Engineering of Organic Dyes Containing N-Aryl Carbazole Moiety for Solar Cell. Tetrahedron 2007, 63, 1913-1922.

(11) Wang, Z.-S.; Koumura, N.; Cui, Y.; Takahashi, M.; Sekiguchi, H.; Mori, A.; Kubo, T.; Furube, A.; Hara, K. HexylthiopheneFunctionalized Carbazole Dyes for Efficient Molecular Photovoltaics: Tuning of Solar-Cell Performance by Structural Modification. Chem. Mater. 2008, 20, 3993-4003.

(12) Ooyama, Y.; Shimada, Y.; Ishii, A.; Ito, G.; Kagawa, Y.; Imae, I.; Komaguchi, K.; Harima, Y. Photovoltaic Performance of DyeSensitized Solar Cells Based on A Series of New-Type DonorAcceptor $\pi$-Conjugated Sensitizer, Benzofuro[2,3-c] oxazolo(4,5-1)Carbazole Fluorescent Dyes. J. Photochem. Photobiol. A 2009, 203, 177-185.

(13) Hara, K.; Kurashige, M.; Dan-Oh, Y.; Kasada, C.; Shinpo, A.; Suga, S.; Sayama, K.; Arakawa, H. Design of New Coumarin Dyes Having Thiophene Moieties for Highly Efficient Organic DyeSensitized Solar Cells. New J. Chem. 2003, 27, 783-785.

(14) Horiuchi, T.; Miura, H.; Sumioka, K.; Uchida, S. High Efficiency of Dye-Sensitized Solar Cells Based on Metal-Free Indoline Dyes. J. Am. Chem. Soc. 2004, 126, 12218-12219.

(15) Furube, A.; Katoh, R.; Hara, K.; Sato, T.; Murata, S.; Arakawa, H.; Tachiya, M. Lithium Ion Effect on Electron Injection From a Photoexcited Coumarin Derivative Into $\mathrm{A} \mathrm{TiO}_{2}$ Nanocrystalline Film Investigated by Visible-to-IR Ultrafast Spectroscopy. J. Phys. Chem. B 2005, 109, 16406-16414.

(16) Wang, Z.-S.; Cui, Y.; Dan-Oh, Y.; Kasada, C.; Shinpo, A.; Hara, K. Molecular Design of Coumarin Dyes for Stable and Efficient Organic Dye-Sensitized Solar Cells. J. Phys. Chem. C 2008, 112, 17011-17017.

(17) Alibabaei, L.; Kim, J.-H.; Wang, M.; Pootrakulchote, N.; Teuscher, J.; Di Censo, D.; Humphry-Baker, R.; Moser, J.-E.; Yu, Y.-J.; Kay, K.-Y.; et al. Molecular Design of Metal-Free-D- $\pi$-A Substituted Sensitizers for Dye-Sensitized Solar Cells. Energy Environ. Sci. 2010, 3, 1757-1764.

(18) Kuang, D.; Uchida, S.; Humphry-Baker, R.; Zakeeruddin, S. M.; Grätzel, M. Organic Dye-Sensitized Ionic Liquid Based Solar Cells: Remarkable Enhancement in Performance Through Molecular Design of Indoline Sensitizers. Angew. Chem., Int. Ed. 2008, 47, 1923-1927.

(19) Dentani, T.; Kubota, Y.; Funabiki, K.; Jin, J.; Yoshida, T.; Minoura, H.; Miura, H.; Matsui, M. Novel Thiophene-Conjugated Indoline Dyes for Zinc Oxide Solar Cells. New J. Chem. 2009, 33, 93101.

(20) Liu, B.; Zhu, W.; Zhang, Q.; Wu, W.; Xu, M.; Ning, Z.; Xie, Y.; Tian, H. Conveniently Synthesized Isophorone Dyes for High Efficiency Dye-sensitized Solar Cells: Tuning Photovoltaic Performance by Structural Modification of Donor Group in Donor $-\pi-$ Acceptor System. Chem. Commun. 2009, 1766-1768.

(21) Wu, Y.; Zhu, W. Organic Sensitizers from D- $-\pi-A$ to D-A $-\pi-$ A: Effect of the Internal Electron-Withdrawing Units on Molecular Absorption, Energy Levels and Photovoltaic Performances. Chem. Soc. Rev. 2013, 42, 2039-2058.

(22) Cai, S.; Hu, X.; Zhang, Z.; Su, J.; Li, X.; Islam, A.; Han, L.; Tian, H. Rigid Triarylamine-Based Efficient DSSC Sensitizers With High Molar Extinction Coefficients. J. Mater. Chem. A 2013, 1, 4763-4772.

(23) Sayama, K.; Sugino, M.; Sugihara, H.; Abe, Y.; Arakawa, H. Photosensitization of Porous $\mathrm{TiO}_{2}$ Semiconductor Electrode With Xanthene Dyes. Chem. Lett. 1998, 753-754.

(24) Hattori, S.; Hasobe, T.; Ohkubo, K.; Urano, Y.; Umezawa, N.; Nagano, T.; Wada, Y.; Yanagida, S.; Fukuzumi, S. Enhanced Energy and Quantum Efficiencies of a Nanocrystalline Photoelectrochemical Cell Sensitized with a Donor-Acceptor Dyad Derived from Fluorescein. J. Phys. Chem. B 2004, 108, 15200-15205.

(25) Tian, H.; Yang, X.; Chen, R.; Pan, Y.; Li, L.; Hagfeldt, A.; Sun, L. Phenothiazine Derivatives For Efficient Organic Dye-Sensitized Solar Cell. Chem. Commun. 2007, 3741-3743.
(26) Mann, J. R.; Gannon, M. K.; Fitzgibbons, T. C.; Detty, M. R.; Watson, D. F. Optimizing the Photocurrent Efficiency of DyeSensitized Solar Cells Through The Controlled Aggregation of Chalcogenoxanthylium Dyes on Nanocrystalline Titania Films. J. Phys. Chem. C 2008, 112, 13057-13061.

(27) Kim, B.-G.; Chung, K.; Kim, J. Molecular Design Principle of All-Organic Dyes for Dye-Sensitized Solar Cells. Chem.-Eur. J. 2013, 19, 5220-5230.

(28) Feng, Q.; Jia, X.; Zhou, G.; Wang, Z.-S. Embedding An Electron Donor or Acceptor into Naphtho[2,1-b:3,4- $\left.b^{\prime}\right]$ Dithiophene Based Organic Sensitizers for Dye-Sensitized Solar Cells. Chem. Commun. 2013, 49, 7445-7447.

(29) Yella, A.; Lee, H.-W.; Tsao, H. N.; Yi, C.; Chandiran, A. K.; Nazeeruddin, M. K.; Diau, E. W.-G.; Yeh, C.-Y.; Zakeeruddin, S. M.; Grätzel, M. Porphyrin-Sensitized Solar Cells with Cobalt (II/III)Based Redox Electrolyte Exceed 12\% Efficiency. Science 2011, 334, 629-634.

(30) Mathew, S.; Yella, A.; Gao, P.; Humphry-Baker, R.; Curchod, B. F. E.; Ashari-Astani, N.; Tavernelli, I.; Rothlisberger, U.; Nazeeruddin, Md. K.; Grätzel, M. Dye-Sensitized Solar Cells with 13\% Efficiency Achieved Through the Molecular Engineering of Porphyrin Sensitizers. Nature Chem. 2014, 6, 242-247.

(31) Yella, A.; Mai, C.-L.; Zakeeruddin, S. M.; Chang, S.-H.; Hsieh, C.-H.; Yeh, C-Y; Grätzel, M. Molecular Engineering of Push-Pull Porphyrin Dyes for Highly Efficient Dye-Sensitized Solar Cells: The Role of Benzene Spacers. Angew. Chem., Int. Ed. 2014, DOI: 10.1002/ anie.201309343.

(32) Haid, S.; Marszalek, M.; Mishra, A.; Wielopolski, M.; Teuscher, J.; Moser, J-E; Humphry-Baker, R.; Zakeeruddin, S. M.; Grätzel, M.; Bäuerle, P. Significant Improvement of Dye-Sensitized Solar Cell Performance by Small Structural Modification in $\pi$-Conjugated Donor-Acceptor Dyes. Adv. Funct. Mater. 2012, 22, 1291-1302.

(33) Wu, Y.; Marszalek, M.; Zakeeruddin, S. M.; Zhang, Q.; Tian, H.; Grätzel, M.; Zhu, W. High-Conversion-Efficiency Organic DyeSensitized Solar Cells: Molecular Engineering on D-A- $\pi$-A Featured Organic Indoline Dyes. Energy Environ. Sci. 2012, 5, 8261-8272.

(34) Zhu, W.; Wu, Y.; Wang, S.; Li, W.; Xi, X.; Chen, J.; Wang, Z.-S.; Tian, H. Organic D-A- $\pi$-A Solar Cell Sensitizers with Improved Stability and Spectral Response. Adv. Funct. Mater. 2011, 21, 756-763.

(35) Li, J.-Y.; Chen, C.-Y.; Lee, C.-P.; Chen, S.-C.; Lin, T.-H.; Tsai, H.-H.; Ho, K.-C.; Wu, C. G. Unsymmetrical Squaraines Incorporating the Thiophene Unit for Panchromatic Dye-Sensitized Solar Cells. Org. Lett. 2010, 12, 5454-5457.

(36) Kim, J.-J.; Choi, H.; Lee, J.-W.; Kang, M.-S.; Song, K.; Kang, S. O.; Ko, J. A. Polymer Gel Electrolyte to Achieve $\geq 6 \%$ Power Conversion Efficiency with A Novel Organic Dye Incorporating A Low-Band-Gap Chromophore. J. Mater. Chem. 2008, 18, 5223-5229.

(37) Tang, Z.-M.; Lei, T.; Jiang, K.-J.; Song, Y.-L.; Pei, J. Benzothiadiazole Containing D- $\pi$-A Conjugated Compounds for Dye-Sensitized Solar Cells: Synthesis, Properties, and Photovoltaic Performances. Chem. Asian J. 2010, 5, 191-1917.

(38) Stephens, P. J.; Devlin, F. J.; Chablowski, C. F.; Frisch, M. J. Ab Initio Calculation of Vibrational Absorption and Circular Dichroism Spectra Using Density Functional Force Fields. J. Phys. Chem. 1994, 98, 11623-11627.

(39) Rassolov, V.; Pople, J. A.; Ratner, M. A.; Windus, T. L. 6-31G* Basis Set For Atoms K Through Zn. J. Chem. Phys. 1998, 109, 12231229.

(40) Frisch, M. J.; Trucks, G. W.; Schlegel, H. B.; Scuseria, G. E.; Robb, M. A.; Cheeseman, J. R.; Scalmani, G.; Barone, V.; Mennucci, B.; Petersson, G. A.; et al. Gaussian 09; Gaussian, Inc., Wallingford CT, 2009. 